\title{
Um historiador do Brasil: István Jancsó ${ }^{1}$
}

An Historian of Brazil: István Jancsó

\section{Denis Antônio de Mendonça Bernardes \\ Professor no Departamento de Serviço Social da Universidade Federal de Pernambuco (CCSA) UFPE - Recife/Brasil)} e-mail:denisb@ufpe.br
Resumo

De um ponto de vista ao mesmo tempo pessoal e acadêmico, este texto evoca a memória e a obra de István Jancsó, particularizando-a em ideias centrais que, de algum modo, se relacionam com sua visão da Independência do Brasil como um processo histórico não-local.

\section{Abstract}

From a point of view at the same time academic and personal, this article deals with Istvan Jancsó's memory and work. It focuses specifically in his interpretation of Brazilian independence as a non-local historical process.

Palavras-chave

Independência, nação, István Jancsó

Keywords:

Brazilian Independence, nation, István Jancsó 
CSO, István e PIMENTA, João Paulo Garrido. "Peças de um mosaico (ou apontamentos para o estudo da emergência da identidade nacional brasileira)". In: MOTA, Carlos Guilherme (Org.). Viagem incompleta. Formação história. A experiência brasileira. São Paulo: Editora SENAC, 2000. p.138.
Quero agradecer, desde logo, pelo convite que me foi feito para escrever este texto. Faço- 0 , certamente, com sentimentos diversos. 0 sentimento de uma grande perda, de uma ausência física apenas mitigada por uma presença que, contudo, existe no legado intelectual e humano do amigo que se foi, e ao qual somos devedores de tantas lições de vida e de saber histórico. Legado que nos une, colocando-nos de uma maneira tão especial, tão carregada de nossos próprios sentimentos e lembranças, diante da memória e da matéria das nossas vidas: 0 ofício do historiador. 0 sentimento de que somos parte de um ato muito especial, dos mais essenciais da humana existência: a evocação de um amigo não mais presente fisicamente. Ato atravessado, ainda, pela tarefa gratificante do exame do seu legado intelectual no que é igualmente nossa paixão e nosso desafio: pensar o Brasil como objeto histórico.

Não é deslocado, creio, assinalar que a publicação deste $2^{\circ}$ Fórum da Revista Almanack como o primeiro evento da parceria entre o Centro de Estudos do Oitocentos e a mencionada revista, possui um significado especial. Na escolha do Rio de Janeiro como local onde se realizou o evento do qual resulta esta publicação, percebo um elo com uma das contribuições fundamentais de István Jancsó no esforço de repensar a formação do Estado e da nação no Brasil. No texto que escreveu em parceria com João Paulo Garrido Pimenta, texto que se tornou referência fundamental, como tantos outros de sua autoria, deparamos quase em seu início com esta fina percepção de que o espaço é uma componente essencial da trama política:

Essa construção de territórios (e da sua consequente representação), dotados de tessituras sociais próprias pressupondo precisa territorialidade, estabeleceu marcos das identidades coletivas no universo luso-americano, tanto definindo (recorrendo à expressão de Anderson) as rotas de peregrinação, quanto os confrontantes nos quais essas identidades se espelhavam. ${ }^{2}$

Pois no Rio de Janeiro estava um dos pólos das tessituras sociais que, com todas as conhecidas tensões do processo da Independência, foi o ponto de convergência das "abrangências, atlântica, portuguesa, brasílica e local". É como se pelas urdiduras da vida este evento realizasse uma das mais caras e instigantes formulações de István Jancsó: a do mosaico das pátrias luso-americanas.

É muito difícil, para mim, separar ou conter o fluxo da lembrança da pessoa de István Jancsó e da convivência intelectual e humana que mantivemos durante vários anos, da tarefa de assinalar algumas de suas principais contribuições para os recentes estudos sobre nossa formação histórica, notadamente aquelas focadas na formação do Estado e da nação. Os que com ele convivemos, com maior ou menor intensidade, sabemos o quanto sua vida foi marcada pela paixão do trabalho intelectual, pelo ensino, pela orientação de graduandos e pós-graduandos, pela organização dos meios de um trabalho coletivo que, coerente com sua citada visão do processo da espacialidade, da construção de territórios, agregava as gentes dos Brasis e dos além Brasis. Embora não desenvolva inteiramente este fluxo da memória, é impossivel não dizer o quanto a redação deste texto está marcada por uma materialidade na qual a vida, em sua concretude de encontros, de gestos, de palavras, de partilhas tantas é, ao mesmo tempo, uma presença e um desafio. É que István foi, também, um grande articulador de sociabilidades intelectuais, um dirigente intelectual, com um especial senso de 
Ver a descrição feita pelo próprio István do que era a dinâmica da sua sala no Departamento de História da USP, em Um historiador do Brasil... Op. Cit., p.255.

Além dos sólidos apoios documentais que estão presentes em seus diversos trabalhos, dos projetos de edições de fontes, alguns infelizmente não realizados, devem ser lembradas as duas úteis cronologias que dirigiu e fez realizar por estudantes de graduação: Cronologia de História do Brasil Colonial (1500-1831). São Paulo: FFLCH-USP, 1994 e Cronologia de História do Brasil Monárquico (1808-1889). São Paulo: Humanitas/FFLCH/USP, 2000. Quantos estudantes tiveram na realização destes trabalhos uma especial formação no ofício do historiador e não determinaram a partir daí suas escolhas de vida? Neste campo da edição de fontes a ação de István concretizou-se na magnífica Documento Uspiana, dirigida com Pedro Puntoni. Os quatro títulos já publicados pela importância dos textos e pela qualidade crítica das edições colocam esta iniciativa entre as de primeiro plano na edição de fontes históricas no Brasil e alhures: NORONHA, José Monteiro de. Roteiro da viagem da cidade do Pará até as últimas colônias do sertão da província (1768). Introdução e notas de Antonio Porro. São Paulo: Edusp, 2006; ANTONIL, André João. Cultura e Opulência do Brasil por suas Drogas e Minas. Introdução e notas de Andrée Mansuy Diniz Silva. São Paulo: Edusp,2007; BARATA, Cipriano. Sentinela da Liberdade e outros escritos (18211835). Organização e edição de Marco Morel. São Paulo: Edusp, 2008; VIDE, Sebastião Monteiro da. Constituições Primeiras do Arcebispado da Bahia. Estudo introdutório e edição de Bruno Feitler e Evergton Sales Souza. São Paulo: Edusp, 2010.

5

Rio de Janeiro: Universidade Federal

Fluminense, 1974. Posteriormente, editada com ajustes em livro, como: Na Bahia contra o Império: História do Ensaio de Sedição de 1798. São Paulo: Hucitec, 1996. organização, um mestre de obras que sabia planejar e realizar. Sabia convocar e dirigir os que podiam participar com seus próprios meios e saberes da construção do edifício cuja matéria e objeto eram coletivos. 0 mais coletivo dos objetos que foi, é e será a casa inacabada das gerações do passado, do presente e do futuro: a Nação brasileira. A quantos de nós ele acolheu, e para quantos dos mais jovens foi um guia exigente e respeitoso? Impossivel não rememorar sua sala no Departamento de História da USP e, depois, no Instituto de Estudos Brasileiros, nas quais parte de sua biblioteca estava disponivel para os estudantes da graduação e para seus orientandos da pós-graduação. ${ }^{3}$ Quantas lembranças estão na memória de todos que as frequentaram. E o quanto poderia ser dito sobre as diversas reuniões do Projeto Temático Brasil: Formação do Estado e da Nação, em uma das salas do Instituto de Estudos Brasileiros. Reuniões todas gravadas e pacientemente transcritas por André Nicácio Lima, cujo conteúdo precisa ser um dia retomado. Sob a batuta de István, em sucessivas ocasiões, vivíamos um processo coletivo de elaboração de um projeto historiográfico no qual nada estava predeterminado e no qual a contribuição de cada um se dava em toda liberdade. A palavra era solta, a atenção a fala de cada um era uma norma não escrita, mas executada como uma das mais importantes regras da nossa convivência. A palavra de István, vinda após uma atenta escuta, paradoxalmente mais aguçada por sua semi-surdez causada pela tortura que sofrera em sua prisão durante a ditadura civil-militar instaurada em 1964, muitas vezes dava a síntese de nossas falas e propunha novas questões que eram retomadas até chegarmos a um ponto de acordo jamais marcado pela fala de uma autoridade institucional, mas sim pelo reconhecimento de uma longa e maturada elaboração historiográfica que incluía tanto sua experiência de vida, quanto suas vastas leituras, sua cultura geral e sua constante preocupação com a solidez documental. ${ }^{4}$

Tudo isto pode parecer a repetição de alguns clichês acadêmicos, a reiteração dos ritos e fórmulas sob os quais fomos formados e que fazem parte de uma cultura da corporação com seus códigos, seus ditos e não ditos, seu arsenal linguístico. Penso, no entanto, que sob este aparente ritual algo mais profundo se passava. E não serei o único, entre os que conviveram com István a pensar assim. Não estou a idealizar uma realidade para construir uma hagiografia que não tem lugar, que ele próprio recusaria, com toda razão e, certamente, com um irônico sorriso. Ele que, com toda sua generosidade humana e intelectual, tantas vezes afirmou suas discordâncias, provocou polêmicas e viveu rupturas na academia e fora dela.

0 professor Marco Pamplona, no importante e belo texto que antecede a este aponta, com muita propriedade, algumas das ideias mestras das elaborações feitas por István Jancsó nos seus vários trabalhos, desde sua tese de livre docência, Contradições, tensões, conflito - a Inconfidência Baiana de $1798^{5}$, até os que se seguiram em seus diversos escritos. Sem repetir inteiramente o que está em seus textos, os retomarei de uma maneira muito sintética, buscando depois apontar o quanto influenciaram diversos trabalhos de outros autores, alguns de seus orientandos e o quanto ainda permanecem como inspiração para o presente e o futuro. Inclusive, o quanto são importantes para a releitura de toda uma historiografia consagrada com a qual István sempre dialogou.

$\mathrm{Na}$ atenta leitura feita e apresentada pelo professor Marco Pamplona estão postas as linhas mestras das reflexões de István Jancsó: sedição colonial, a resignificação, na Bahia do final do século XVIII, do conceito 
PAMPLONA, Marco A. Dialogando com a obra de István Jancsó: algumas considerações sobre a contribuição desse historiador do Brasil para os debates recentes da historiografia. Almanack, Guarulhos, n.02, p.07, 2 semestre de 2011.

7

Para as referências, ver notas 12 a 18 do texto de Marco A. Pamplona acima citado

8

MOREL, Marco; SLEMIAN, Andréa; LIMA, André Nicário. Um historiador do Brasil... 0p. Cit.,p.306.

9

VARNHAGEN, Francisco Adolfo de. História da Independência do Brasil até ao reconhecimento pela antiga metrópole, compreendendo, separadamente, a dos sucessos ocorridos em algumas províncias até essa data. $6^{\text {a }}$ ed. Brasília: INL, 1972.

10

A contagem do número de páginas está baseada na edição citada na nota anterior.

11

RODRIGUES, José Honório. Independência: revolução e contra-revolução. Rio de Janeiro: Francisco Alves, 1975-1976. Vol.1 - A evolução política. vol.2 - Economia e sociedade. vol.3 - As forças armadas. vol.4 - A liderança nacional. vol.5 - A política internacional.

12

0 volume 5, intitulado a liderança nacional, considera apenas os personagens que estavam próximos a D. Pedro, dividindo-os entre $A$ grande liderança. Os protagonistas e A liderança menor. Os deuteragonistas. Os outros capítulos intitulam-se: 0 povo e a Independência, 0 clero e a Independência, A imprensa e a Independência. de liberdade, a singularidade desse tempo colonial atlântico (o tempo da sedição), a passagem da conspiração à transgressão, ("No trajeto de conspiração à transgressão, adensou-se socialmente o desconforto político criado pela percepção cotidiana da crise em curso, a rebeldia tornou-se organizada e irrompeu no espaço da vida pública"6); centros de convergência do "continente Brasil"; mosaico das pátrias luso-americanas, abrangências, atlântica, portuguesa, brasílica e local, ou seja, a ideia de distintas abrangências que, gestadas ao longo do período colonial, ganharam nova dimensão a partir de 1808 e, sobretudo, quando da criação do Reino do Brasil e que o obrigava a ser sintese das partes, princípio organizador da diversidade brasílica e um corpo político de feições próprias no interior da monarquia portuguesa ${ }^{7}$.

Todas estas formulações, para retomar uma expressão do próprio István, iluminam o que está iluminado ${ }^{8}$, mas aí reside a originalidade de sua contribuição. Foi ao retomar, primeiro a sedição baiana de 1798, e em seguida o processo de formação do Estado e da Nação no Brasil, que ele pode avançar em sua reflexão. 0 que já era sabido ganha nova inteligibilidade em um esforço de construir uma grade interpretativa que o ultrapassa.

Tomemos, por exemplo, o processo da Independência, tal como se apresentou antes e depois do Sete de Setembro. Uma imensa bibliografia, de variadas matrizes, já se ocupara deste tema, com maior ou menor solidez documental e profundidade analítica. Mas, qual era o foco que iluminava quase todos os estudos sobre tal processo, especialmente os mais prestigiosos? A centralidade do papel de D. Pedro e o Rio de Janeiro como o centro irradiador de todo o processo. Tal é o fio condutor da obra de Francisco Adolfo de Varnhagen. ${ }^{9}$ Daí a própria estrutura da sua narração dedicando a parte maior dos dez capítulos (363 páginas) ao que se passou entre Lisboa e o Rio de Janeiro desde a instalação das Cortes à regência de $D$. Pedro até o tratado de reconhecimento da Independência em 1825. Em seguida, vem uma parte denominada As províncias, na qual, em 138 páginas são descritos os acontecimentos que se passaram na Bahia, Sergipe, Alagoas, Pernambuco, Paraiba, Rio Grande do Norte, Ceará, Maranhão e Pará. ${ }^{10}$

José Honório Rodrigues, embora situado em uma posição política e interpretativa em oposição à de Varnhagen, retoma o mesmo foco de análise: centralidade do papel de D. Pedro e do Rio de Janeiro em todo o processo da Independência. Em ambos os autores, apesar das suas já lembradas divergentes posições políticas e interpretativas, toda dissidência local à política de $\mathrm{D}$. Pedro e de José Bonifácio recebe o labéu de antinacional. A obra de José Honório Rodrigues sobre a Independência é, como sabido, muito mais ampla, sólida e complexa que a de Francisco Adolfo de Varnhagen, desdobrando-se em cinco volumes dedicados a aspectos específicos de todo o seu processo. ${ }^{11}$ No entanto, sua visão centralizadora é ainda mais radical que a de Varnhagen. No volume 1, dedicado a Evolução política, o capítulo 4 intitula-se Evolução política nacionalista (119 páginas), dedicado aos acontecimentos que tiveram lugar no Rio de Janeiro, em São Paulo e Minas Gerais, desde a volta de D. João VI a Portugal até 1823.0 capítulo 5, intitulado Evolução política provincial (54 páginas) não apenas apresenta este desigual tratamento no número de páginas, mas traz subtítulos como Unidade e dissidência e A apostasia e a lealdade provinciais. ${ }^{12}$

Ora, é evidente que havia uma diversidade espacial e, mesmo temporal, ambas fundamentais entre a corte no Rio de Janeiro e as 
13

JANCSÓ, István e PIMENTA, João Paulo Garrido. Op. Cit., p.135-136.

14

Frei Joaquim do Amor Divino Caneca intitulou a terceira de suas cartas de Cartas de Pítia da Damão: Sobre os projetos despóticos do Ministério do Rio de Janeiro. Escrita depois de junho de 1823, nela frei Caneca faz duras críticas à criação da Ordem do Cruzeiro, à oposição de José Bonifácio de Andrada e Silva ao desejo dos liberais do juramento prévio da futura Constituição por parte do Imperador, à devassa mandada instaurar contra José Clemente Pereira, Gonçalves Ledo e seu grupo (2 de novembro de 1822), à convocação do Conselho de Procuradores (16 de fevereiro de 1822), ao decreto de 18 de junho de 1822, criando Juizes de Fato para julgamento dos crimes de abusos de liberdade de imprensa, ao fechamento dos jornais $O$ Periquito, 0 Correio do Rio de Janeiro, A Malagueta e ao atentado sofrido pelo seu redator Luís Augusto May (5 de junho de 1823), e defende uma larga autonomia para as provincias que, segundo ele, deveriam possuir suas próprias Marinhas e não depender para suas defesas da Marinha do Império. Ainda, em suas palavras: "Sim meu caro Damão, uma inquisição política se abriu na corte, e mandou-se abrir aqui e no Maranhão contra os republicanos, carbonários, etc.; pelos quais entendem todos os homens que não pensam como o ministério. Foram no Rio presas mais de trezentas pessoas, que povoam ainda a cadeia, Ilha das Cobras e Lage (sic); outros foram deportados para fora do Brasil; e outros querendo escapar a esta proscrição de Sylla (sic), emigraram de sua pátria, e foram procurar refúgio e gasalhado em terra alheia". Obras Politicas e Literárias de Frei Joaquim do Amor Divino Caneca. Colecionadas pelo Comendador Antônio Joaquim de Mello. Recife: Assembleia Legislativa do Estado, 1972. Edição fac-similar da edição de 1875 , tomo, II, p.314. províncias. 0 reconhecimento desta diversidade não constitui, em si, nenhum problema. Ao contrário, ele se impõe. 0 problema está no foco dado a tal diversidade. Nos autores citados, as províncias se opõem ao todo, que por suposto, é o que se passava na Corte. A grande contribuição de István é justamente o de haver elevado tal diversidade a um novo patamar interpretativo, com a noção do todo e das partes. Leiamos, nas palavras de István Jancsó, como tal diversidade ganha outro foco, e o que já estava iluminado ganha uma nova luz:

Para os homens que viveram a dissolução do império português na América, a percepção da crise não se deu de modo uniforme, com o que das diferentes percepções resultaram múltiplos projetos políticos, cada qual, expondo com maior ou menor nitidez, o esboço da comunidade humana cujo futuro projetavam. Vem daí que aos projetos de futuro contrapostos corresponderam outras tantas definições de Estado, cidadania, condições de inclusão e exclusão, padrões de lealdade e critérios de adesão, cada qual descrevendo elementos do pacto tido como adequado para transformar comunidades em nação. Dessa forma, nunca se deve esquecer que a provisoriedade característica do periodo traduziu-se na coexistência não apenas de ideias relativas ao Estado, mas também à nação e às correspondentes identidades políticas coletivas, eventualmente reveladoras de tendências à harmonização entre si ou, quando não, expressando irredutibilidades portadoras de alto potencial de conflito. ${ }^{13}$

Todo este mundo dos conflitos, das oposições, da diversidade de projetos, das diversas concepções de Estado e de nação, ganha outra inteligibilidade, outra chave interpretativa que não anula a concretude do objeto, mas ao contrário torna mais exigente a atenção para a complexidade e especificidade de cada situação em confronto. Ao mesmo tempo, a trama das especificidades com o projeto que buscava incorporá-las ou, no limite, anulá-las, aparece sob outra luz, igualmente mais complexa e rica.

Não há, ainda, uma prévia posição que buscaria nomear os bons projetos de Estado e de nação e os maus projetos. Não há o lançamento de anátemas sobre os que seriam os maus patriotas, os apóstatas ou o prêmio aos bons e leais. Sendo, em geral, os primeiros os que se recusavam a alinharem-se submissos ao projeto do Ministério do Rio de Janeiro ${ }^{14}$, e os segundos os que nada recusavam ao mesmo e, seja na corte, seja nas províncias, eram seus agentes e sustentáculos.

Ao refletir sobre o texto acima citado percebo o quanto ele nos permite pensar um amplo arco de movimentos que inclui a Inconfidência Mineira (1789), a pretendida sedição da Sociedade Literária do Rio de Janeiro (1794), a sedição baiana (1798), a Revolução de 1817, a Confederação do Equador (1824), a Cabanagem no Pará (1835), a Farroupilha no Rio Grande do Sul (1835-1845), a Sabinada na Bahia (1837-1838), a Praieira em Pernambuco (1848), sem falar de uma série de outros movimentos que tiveram lugar em distintos momentos do século XIX. E não se trata de uma pretensão interpretativa que venha a ser a chave que tudo pode abrir e revelar. 0 que está proposto são elementos de investigação que, para ganhar sentido pleno, tem que ser confrontados com uma atenta investigação, em suas especificidades, tanto sociais, quanto econômicas, políticas e mentais.

Obviamente que os diversos textos elaborados por István Jancsó, especialmente os voltados ao tema do Estado e da nação, não surgiram do nada. São, ao contrário, o produto de um diversificado trajeto intelectual e pessoal, que incluiu deslocamentos espaciais desde sua terra de nascimento, a Hungria, e suas várias andanças pelo Brasil e, depois, um novo período europeu, em sua maturidade. Trajeto do qual fazem parte 
"Isso de ensino na formação teórica era uma das vertentes da minha relação com a historiografia. A outra era o trabalho massivo com documentação". MOREL, Marco; SLEMIAN, Andréa; LIMA, André Nicário. Um historiador do Brasil... Op. Cit.,p. 172

16

Fazendo uma revisão do clima intelectual dos anos 60 e $70 \mathrm{diz}$ : "Ninguém compreendia naquela altura que a questão é da qualidade da análise e não da origem do referencial".

17

Naturalmente elas são muitas e variadas. Elas incluem suas leituras juvenis, tão amplas, nas quais a literatura húngara tem um lugar importante, bem como os clássicos gregos e latinos lidos em húngaro, quando adolescente em São Paulo. Incluem, ainda, o fato de ter sido aluno de Sérgio Buarque de Holanda, de Eduardo D'Oliveira França e de Fernando Antônio Novais. Deste último foi aluno e amigo, e com o mesmo partilhou a direção da Coleção Estudos Históricos, da Editora Hucitec. Coleção que se impôs como das mais importantes coleções brasileiras na área da História. A interlocução com Fernando A. Novais está presente em todos os trabalhos de István, e a tese de Novais, Portugal e Brasil na crise do Antigo Sistema Colonial (1771-1808), cuja primeira edição em livro data de 1979, é uma referência constante e sempre reafirmada. Ao fazer uma referência a Pierre Vilar, István pensa na "fantástica possibilidade do bom manejo do marxismo". MOREL, Marco; SLEMIAN, Andréa; LIMA, André Nicário. Um historiador do Brasil... Op. Cit.,p. 182

18

Ibidem, p.296. Os textos a que István aqui se refere são: STUMPF, Roberta. Filhos das minas, americanos e portugueses: identidades coletivas na capitania das Minas Gerais (1763-1792). São Paulo: Hucitec/FAPESP, 2010; e VILAR, Pierre. Hidalgos, amotinados y guerrilleros. Pueblo y poderes en la historia de España. Barcelona: Critica, 1982.

19

"O conhecimento tinha a ver com a vida da gente; e a vida da gente não era a biografia da gente, era a vida da gente, o país, a nação, essas coisas...". Um historiador do Brasil... Op.Cit., p.71.

20

Importa lembrar que István teve também uma passagem pela Paraiba, da qual faz um excelente relato em Um historiador do Brasil... Op. Cit.

21

Ibidem, p.46. Ao justificar para sua mãe porque recusava a carreira de dentista que a família planejara para ele, disse: "Eu quero ver a vida. E a vida é ver História, ver Literatura, a vida é isso". Cf. Ibidem, p.45. o seu longo trabalho docente, a preocupação com a formação dos seus estudantes, da moçada como ele gostava tanto de dizer..$^{15} 0$ que 0 conduzia a exigências teóricas e de pesquisa que colocavam a ele e aos seus alunos diante da melhor historiografia, e no trato direto com as fontes. ${ }^{16}$ Neste particular, sua trajetória de vida - tão rica e diversa - e suas dívidas intelectuais estão muito bem registradas neste livro tão importante que contém os longos depoimentos dados a Marco Morel, Andréa Slemian e André Nicácio Lima. Quero apenas destacar uma referência feita por ele próprio a uma destas dividas intelectuais, creio que uma das mais especiais ao longo do seu trabalho. ${ }^{17}$

Ao responder a uma pergunta sobre a nação como projeto, para aquele livro, diz:

Agora, é neste sentido que eu creio que começar a buscar um entendimento de alguns aspectos dessa questão (a nação como projeto) através do estudo da questão identitária, pode ser útil. Porque (sic): como objetivar subjetividades? Este é um desafio extraordinário; através do que? Através da sua objetivação em documentos, ou em formas de expressar as coisas. Ainda que você saiba que as identidades, inclusive as identidades de tipo nacional, são instáveis, sujeitas a mudanças, não são únicas, seu significado tem de ser confrontado com outros, com critérios de etnicidade, essa coisa toda. Ainda assim, a vigência de determinadas formas de autoidentificação pode ser muito útil para compreensão daquilo que cabe perguntar sobre a construção das estruturas nacionais. Porque as estruturas nacionais não são coisas fixas, materiais. Elas também são mutantes, e temos de acompanhar mutações no interior de coisas mutantes. Mutação de identidade, mutação de estruturas. A vantagem metodológica que eu vejo em buscar a abordagem por este viés é que a variável identitária pode ser recortada. A primeira experiência de pesquisa nesse sentido, da qual participei, foi o mestrado da Roberta [Stumpf] a partir de um método anunciado pelo [Pierre] Vilar naquele livro Hidalgos. Amotinados y guerrilleros. Porque, de repente, você percebe que também há regularidades. ${ }^{18}$

Pierre Vilar, juntamente com Fernando Antonio Novais, é o autor mais citado em seu depoimento já referido. 0 primeiro está citado vinte e três vezes e o segundo quarenta e cinco vezes. Uma notação quantitativa em si, plena de significado, e que pode suscitar vários desdobramentos.

Não parece deslocado pensar que esta centralidade da questão nacional e da identidade nos trabalhos escritos e projetados por István, além dos que orientou e, evidentemente, do Projeto Temático Brasil: Formação do Estado e da nação, tem a ver com algo mais profundo que uma escolha historiográfica. ${ }^{19}$ Sua condição de "húngaro- brasileiro-paulista-baiano, tudo ao mesmo tempo", na definição de Fernando Antonio Novais, lembrada anteriormente por Marco Pamplona, não pode ser dissociada do seu percurso historiográfico. ${ }^{20}$ Espaço, identidade, história, podem ser as palavras chaves que nortearam sua vida e sua produção intelectual. Ele o diz de maneira muito sugestiva ao recordar momentos de sua vida antes de sua entrada no curso de história da USP, muito antes de ser professor:

Um dos livros que eu nunca vou esquecer é o Atlas Geográfico Melhoramentos do Padre Pauwels, lembra? Atlas tosco, mas os lugares estão lá. E depois, quando eu viajei na Real [Aerovias], essa coisa do espaço virou algo que não era só mapa, mas era História porque tinha gente. ${ }^{21}$

Nas diversas andanças e trajetórias da vida de István Jancsó, podemos perceber rotas que conduzem do local ao nacional, e do nacional ao 
Há vários István nestas andanças, que não podem ser tratados aqui. Estão registrados em Um historiador do Brasil, com notações preciosas não apenas para sua biografia, mas para a história brasileira.

23

Ibidem, p.172. local, em um movimento que se integra e que constitui o objeto de seus trabalhos mais importantes. ${ }^{22} 0$ período passado na Bahia, vivido com a paixão que descreveu no depoimento registrado em Um historiador do Brasil, pode ser visto como uma experiência fundante da sua reflexão sobre a formação do Brasil, levando-o a pensar esta formação para além do local, negando-se a relegá-la como uma ruptura menor ou meramente episódica.

0 localismo não o fascinou. 0 que ele buscou pensar e procurou entender foi como uma sedição local situa-se em uma conjuntura que a ultrapassa, que the dá suas possibilidades e seus limites. 0 István Jancsó historiador do Brasil não pode ser separado do István Jancsó que se ocupou da sedição baiana de 1798 .

Para terminar, e com a plena consciência de que muita coisa foi deixada de lado - mas é sempre assim, todo o saber e todo o saber histórico é interminável, o que não tem nenhuma novidade - quero deixar que a fala final deste texto seja do próprio István Jancsó:

Então, essa coisa de historiador é pra mim, um ofício com toda sua complexidade envolvida, e sempre nessa ótica da responsabilidade (responsabilidade parece papo da JUC), essa dimensão cidadã, libertária, que é constitutiva do ofício, sem a qual ele não tem nenhum sentido. ${ }^{23}$ 